AC 2010-1198: CAREER SUCCESS FOR FEMALE STEM FACULTY AT PUBLIC TWO-YEAR INSTITUTIONS

David Koonce, Ohio University

Valerie Conley, Ohio University

Cindy Anderson, Ohio University 


\title{
Career Success for Female STEM Faculty at Public Two-Year Institutions
}

\begin{abstract}
Very limited research exists on the career advancement of STEM female faculty members at public two-year institutions. Within a four-year institutional setting, several employment outcomes, including representation in faculty and leadership positions, tenure status, academic rank, salaries, disciplinary affiliation, research productivity, and others, are identified as markers of academic career advancement.

Community colleges differ dramatically from their four-year counterparts in missions and institutional characteristics. These differences point to the need to re-examine the explanatory power of some findings on STEM career success and advancement outcomes of female faculty in the four-year sector in the context of two-year institutions.

In this paper, we present a study to investigate (1) the extent to which the factors associated with advancement and employment outcomes in the four-year sector translate to the two-year institutional context, and (2) the extent to which there exist other factors affecting female faculty members' employment outcomes that are unique to two-year institutions.

This study examines factors associated with community college female faculty members' academic career success and employment outcomes in STEM fields using secondary data from the 2004 National Study of Postsecondary Faculty (NSOPF).
\end{abstract}

\section{Introduction}

What is academic success? This paper looks into a specific group in higher education, female faculty teaching STEM topics at two year schools. This work is part of a larger NSF ADVANCE grant looking at the overall success of said faculty. In that project, national data will be used to develop a success measure, and faculty will be interviewed to assess the quality of the measure and to identify factors to success not captured by national surveys like NSOPF.

A crucial part of that research is building a success measure. There are several ways that faculty may be seen as successful. There are the traditional three areas of teaching, research and service. And, there are direct advancement measures like rank and tenure. With 2-year school faculty, aspects like highest degree earned and full time employment may also point to the success of a faculty member. This paper presents a preliminary numeric analysis of some basic measures of academic success for STEM faculty members at two-year colleges, broken down by gender. It covers areas of success that are tractable and relevant to the two-year college, and where appropriate, shows comparisons with 4-year schools.

\section{Background}

A significant percent of faculty are based in two-year universities. As of 2003, $43 \%$ of all faculty members in public colleges and universities were employed at public two-year institutions ${ }^{1}$. With respect to gender and STEM, most research focuses on the role of women in 
research universities and on doctoral recipients. Research suggests that on some metrics, women do not share the same success as their male counter parts. For example, women in STEM fields are disproportionately represented at the rank of professor, when compared to the percentage of STEM doctorate degrees awarded ${ }^{2}$. But, trends show that women are making inroads in traditional disciplines like engineering. For example, women's share among full-time tenured or tenure-track faculty in engineering grew from approximately one percent in 1979 to $11 \%$ in $2006^{3}$.

And while the studies that exist on women STEM faculty shed much light on the status of female faculty in four-year institutions, they may not be relevant to the context of public two-year colleges. Two-year colleges differ significantly from their four-year counterparts in missions and institutional characteristics. Research is not an integral part of the institutional mission of community colleges; as a result, few faculty members with doctoral degrees are employed in two-year institutions ${ }^{4}$. In STEM, certain fields are only marginally represented in the two-year sector. For instance, there are very few accredited engineering programs at community colleges; instead, engineering technology programs are common.

Another difference is employment status. As of 2003, two-thirds, or 240,000 community college faculty, were part-time employees, while one-third, or 121,000, were employed full time, compared with part-time employment of $28 \%$ at public four-year institutions and $42 \%$ at private four-year institutions ${ }^{4}$.

The primary source of data for this research is the National Study of Postsecondary Faculty ${ }^{5}$. The NSOPF was a survey conducted four times from 1987 to 2004, by the Department of Education and is a comprehensive collection of data on both faculty and institutions. In each survey a set of questions were asked of a sample of faculty. This data is publically available through the National Center for Educational Ststistics. For this analysis, the 2003-04 survey results were used. In that survey, 1080 schools were surveyed, including 35,000 faculty and staff, with weighted response rates of .86 and .76 , respectively ${ }^{5}$.

The following analysis is based on the NSOPF 2004 survey, and was summarized using the NECS Data Analysis System ${ }^{6}$. To distinguish between two-year and four-year institutions, the variable 2000 Carnegie, 2-year versus 4-year is used. To specify only STEM faculty, the variable Principal field of teaching, NSOPF:88 expanded (26 category) is used with restrictions to the following fields: Agriculture and home economics, Engineering, Biological sciences, Physical sciences, Mathematics, Computer sciences, Economics, Political science, Psychology and Sociology. The choice of STEM fields is based on the science and engineering degrees used by the National Science Foundation ${ }^{3}$.

\section{Rank}

Academic rank is a clear measure of success of a faculty member. While the traditional model of assistant professor to associate professor to full professor is well established in four-year universities, the two year model relies more heavily on instructors. One measure of success of female faculty members at two-year schools would be to see if they hold ranks in similar percentages, or higher percentages to males. Table 1 details the percent of STEM faculty at each academic rank, by sex and Carnegie institution class. The designation of academic rank was 
self determined by respondents; the category of other included the examples: administrative, adjunct and emeritus. At four-year universities, it is clear that female faculty members are much less likely to hold the advanced ranks of professor or associate professor. In contrast, at two-year institutions, women hold the higher ranks at rates comparable to males.

Table 1 Academic Rank for STEM Faculty - Percents ${ }^{5}$

\begin{tabular}{rrrrr}
\cline { 2 - 5 } & \multicolumn{2}{c}{ 4-Year } & \multicolumn{2}{c}{ 2-Year } \\
\hline Academic Rank/Title & Male & Female & Male & Female \\
\hline Professor & 34.9 & 15.6 & 12.3 & 11.2 \\
Associate professor & 21.4 & 17.1 & 5.9 & 6.9 \\
Assistant professor & 17.5 & 24.4 & 4.3 & 4.2 \\
Instructor & 6.1 & 13.8 & 40.5 & 42.8 \\
Lecturer & 4.6 & 7.9 & 2.8 & 1.5 \\
Other title & 15.6 & 21.1 & 34.3 & 33.3 \\
\hline
\end{tabular}

Table 1 only presents the percentages and not the projected numbers, when adjusted for the projected number of individuals in each category, the gender disparity between the ranks for four and two year schools shows large differences. NSOPF projects that in 2004, at the ranks of associate and full professor, males outnumbered females, in STEM disciplines, by 114,627 to 25,441 at four year schools but by 12,503 to 7,566 at two year schools.

\section{Highest Degree}

In general, faculty members at two-year colleges are much less likely to hold doctorates ${ }^{4}$. However, does the percent of female STEM faculty holding doctorates differ from their male counterparts? And, how does any differential that may exist at two year schools differ from differences seen at four year institutions? Table 2 shows that, as expected, the percent of STEM faculty holding doctorates at four-year institutions is much greater than the percent at two-year schools. Interestingly, at both two and four-year institutions, men are $22 \%$ more likely than females to hold doctorates.

Table 2 Highest Degree for STEM Faculty - Percents ${ }^{5}$

\begin{tabular}{rrrrr} 
& \multicolumn{2}{c}{ 4-Year } & \multicolumn{2}{c}{ 2-Year } \\
\cline { 2 - 5 } Highest Degree & Male & Female & Male & Female \\
\hline Doctorate & 81.0 & 66.3 & 18.3 & 15.0 \\
First-professional* & 2.1 & 1.9 & 2.9 & 2.5 \\
Master's & 13.6 & 26.3 & 55.0 & 61.9 \\
Bachelor's & 3.0 & 5.2 & 17.3 & 17.6 \\
Associate's & 0.3 & 0.2 & 3.4 & 2.4 \\
Less than an associate's degree & 0.1 & 0.1 & 3.1 & 0.6 \\
\hline
\end{tabular}

*First professional degrees are defined as: MD, DO, DDS, DMD, LLB, JD, DC, DCM, Pharm.D, Pod.D, DVM, OD, M.Div, HHL or BD. 
Figure 1 shows that while a smaller percentage of female STEM faculty at two-year schools have doctorates, the percentage with graduate degrees is, in fact, higher. This differs from the ratios seen at 4-year schools.

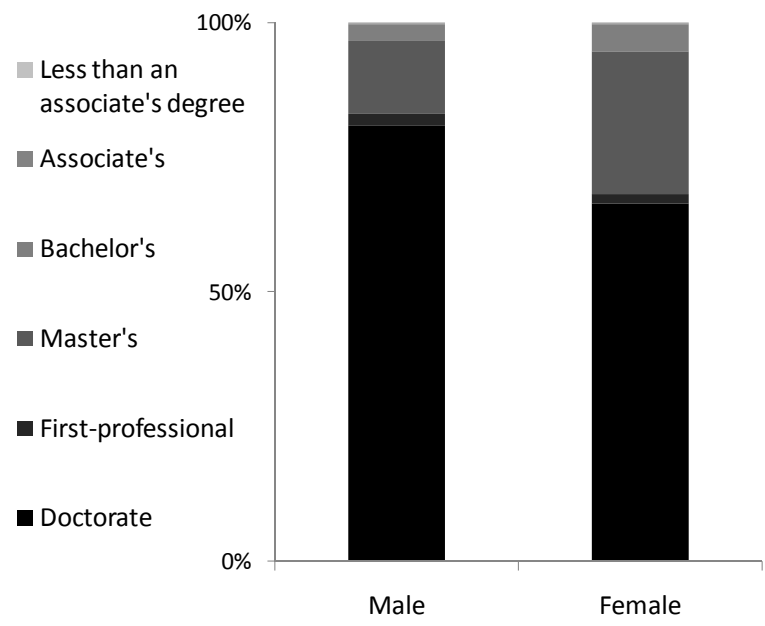

(a) 4-Year

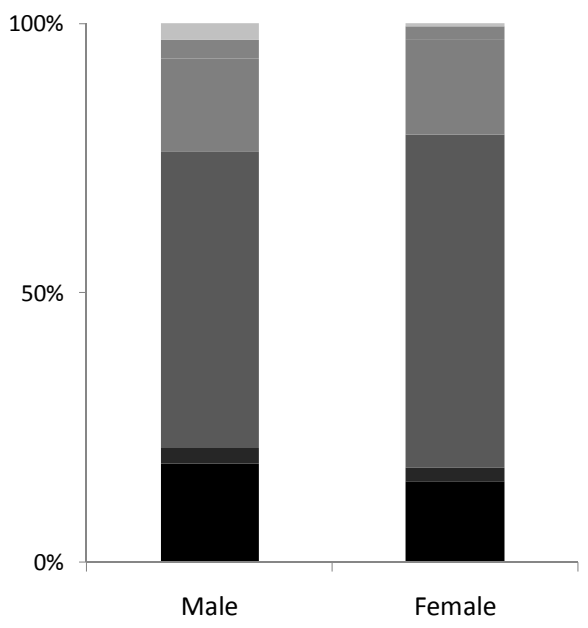

(b) 2-Year

Figure 1 Four-Year and Two-year, Highest Degree for STEM Faculty ${ }^{5}$

\section{Rank versus Degree}

With women less likely than men to hold doctorates at two-year institutions, does that differential make them less likely to attain higher academic ranks? Table 3 shows the percentages at each rank for two year faculty with highest degrees of doctorate, master's and bachelor's degrees.

Table 3 Two-year, Highest Degree vs. Academic Rank for STEM Faculty - Percents ${ }^{5}$

\begin{tabular}{rrrrrcccccc}
\cline { 2 - 11 } & \multicolumn{2}{c}{ Professor } & \multicolumn{2}{c}{$\begin{array}{c}\text { Associate } \\
\text { Professor }\end{array}$} & \multicolumn{2}{c}{$\begin{array}{c}\text { Assistant } \\
\text { Professor }\end{array}$} & \multicolumn{2}{c}{ Instructor } & \multicolumn{2}{c}{ Other } \\
\hline Highest Degree & \multicolumn{1}{c}{ M } & \multicolumn{1}{c}{ F } & \multicolumn{1}{c}{ M } & F & M & F & M & F & \multicolumn{1}{c}{ M } & F \\
\hline Doctorate & 22.1 & 21.5 & 10.7 & 8.7 & 5.1 & 4.3 & 23.2 & 25.3 & 36.2 & 38.4 \\
Master's & 10.7 & 11.1 & 5.2 & 6.6 & 4.6 & 5 & 37.3 & 41.5 & 39 & 34.6 \\
Bachelor's & 5.4 & 1.9 & 2.4 & 0 & 1.3 & 0.5 & 49.7 & 44.3 & 39.7 & 52.1 \\
\hline
\end{tabular}

While the numbers differ, using degree as ordinal and separating the degrees (Figure 2) shows that both male and female faculty hold rank in similar proportions. The largest differences are seen in Figure 2.b, with female faculty holding Master's degrees, who hold associate professor at higher numbers. However, they hold the rank of instructor at a higher percentage. And, a difference is seen in Figure 2.c, where males with Bachelor's degrees hold high rank in a greater percentage. 


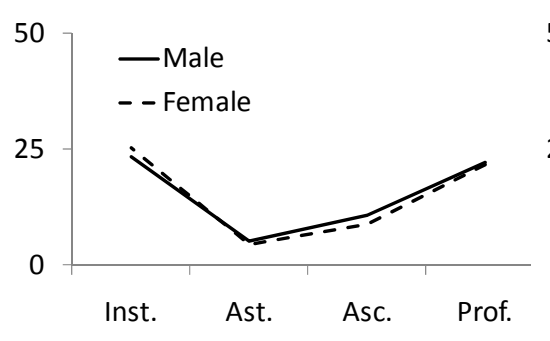

(a) Doctorate

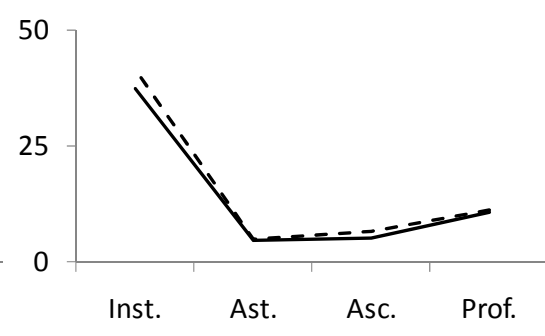

(b) Master's

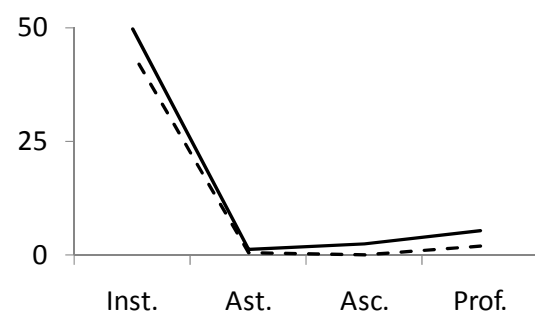

(c) Bachelor's

Figure 2 Two-year, Highest Degree vs. Academic Rank for STEM Faculty ${ }^{5}$

\section{Rank versus Time}

Another way to look at the success is to look at how fast a faculty member progresses through promotion. Table 4 breaks down rank by gender in five year increments, for male and female STEM faculty at two-year schools (the final category includes a 10 year window). In Table 4, each row includes the percentage of faculty (separated by gender) with that experience, at that rank. So, each row should sum to approximately $200 \%$.

Table 4 Two-year, Academic Rank at Years Experience for STEM Faculty - Percents ${ }^{5}$

\begin{tabular}{rlrlllllllll} 
& \multicolumn{1}{c}{} & Professor & \multicolumn{3}{c}{$\begin{array}{c}\text { Associate } \\
\text { Professor }\end{array}$} & \multicolumn{3}{c}{$\begin{array}{c}\text { Assistant } \\
\text { Professor }\end{array}$} & Instructor & Other \\
\hline $\begin{array}{r}\text { Years since first } \\
\text { faculty / }\end{array}$ & $\mathbf{M}$ & $\mathbf{F}$ & $\mathbf{M}$ & $\mathbf{F}$ & $\mathbf{M}$ & $\mathbf{F}$ & $\mathbf{M}$ & $\mathbf{F}$ & $\mathbf{M}$ & $\mathbf{F}$ \\
instructional job & & & & & & & & & & \\
\hline 5 or fewer & 2.9 & 3.3 & 2.1 & 2.8 & 2.8 & 3.8 & 44.4 & 45 & 47.8 & 45.1 \\
$6-10$ & 9.1 & 12.3 & 5.3 & 7.2 & 8 & 4.3 & 40.2 & 41.7 & 37.4 & 34.5 \\
$11-15$ & 9.2 & 2.9 & 12.3 & 11.8 & 2.5 & 1.9 & 32.2 & 47 & 43.8 & 36.3 \\
$16-20$ & 10.1 & 8.6 & 8 & 7.6 & 6.1 & 6.8 & 32.9 & 27.1 & 43 & 50 \\
$21-25$ & 22.5 & 17.5 & 2.9 & 6.4 & 6.6 & 3.5 & 34.2 & 34.4 & 33.8 & 38.3 \\
$26-30$ & 27.7 & 34.4 & 8.3 & 8.9 & 3.7 & 8.3 & 32.6 & 28.1 & 27.6 & 20.3 \\
$31-40$ & 30.3 & 46.3 & 7.4 & 10.3 & 0.5 & 0 & 26.9 & 15.6 & 35 & 27.8 \\
\hline
\end{tabular}

As would be expected, a majority of the two-year faculty in the early years of their career are found in the instructor and other categories. However, as faculty progress, they attain higher ranks in similar percentages.

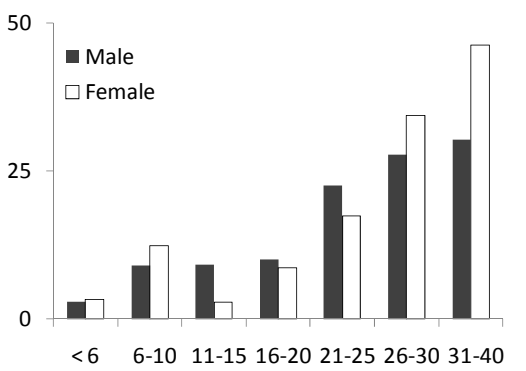

(a) Professor

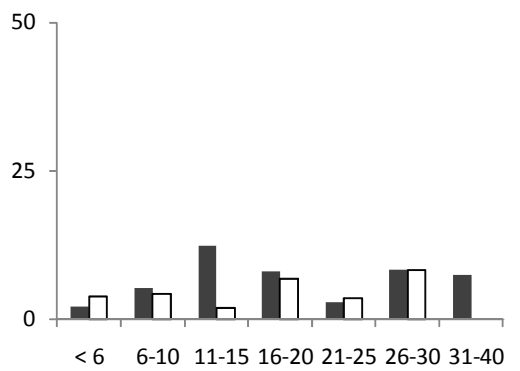

(b) Associate Professor

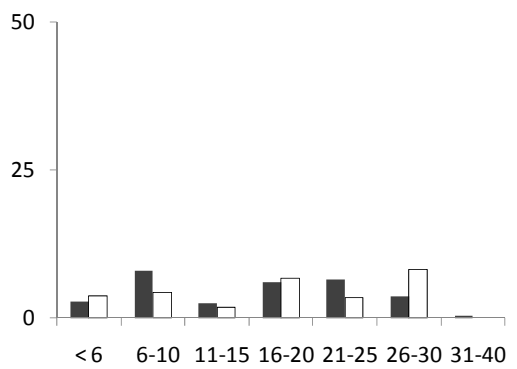

(c) Assistant Professor 
Figure 3 Two-year, Percent at Academic Rank for Years of Experience for STEM Faculty ${ }^{5}$

Figure 3.a shows that for the highest academic rank, female faculty start at a higher percentage, lag behind and eventually catch up and exceed their male colleagues.

\section{Tenure versus Degree}

One measure of success in many colleges is the attainment of tenure. And while many two-year schools do not have tenure systems and most faculty are not tenure track, do tenure track female faculty achieve success at similar rates to male faculty? Table 5 breaks tenure status by gender, and segregates by highest degree.

Table 5 Two-year, Highest Degree vs. Tenure Status for STEM Faculty - Percents ${ }^{5}$

\begin{tabular}{rrrrrrrrr} 
& \multicolumn{2}{c}{ Tenured } & \multicolumn{2}{c}{$\begin{array}{c}\text { On Tenure } \\
\text { Track }\end{array}$} & \multicolumn{2}{c}{$\begin{array}{c}\text { Not on Tenure } \\
\text { Track }\end{array}$} & \multicolumn{2}{c}{$\begin{array}{c}\text { No Tenure } \\
\text { System }\end{array}$} \\
\hline Highest Degree & \multicolumn{1}{c}{ M } & \multicolumn{1}{c}{ F } & \multicolumn{1}{c}{ M } & F & M & F & \multicolumn{1}{c}{ M } & F \\
\hline Doctorate & 38.8 & 30.3 & 7.2 & 7.6 & 44.7 & 45.4 & 9.3 & 16.7 \\
Master's & 22.2 & 22.4 & 6.6 & 6.3 & 56.1 & 49.8 & 15.1 & 21.5 \\
Bachelor's & 9.6 & 5.4 & 3 & 3 & 67.7 & 77.9 & 19.7 & 13.7 \\
\hline
\end{tabular}

Table 5 shows that differences are seen, by rank and gender for faculty at two year schools. Figure 4.a shows that for faculty holding doctorates, males are more likely to hold tenure and females are more likely to be in institutions without tenure systems. For faculty with Master's degrees, Figure 4.b shows that female faculty hold tenure at similar rates as men, but continue the higher percentage at schools without tenure systems. With Bachelor's degrees, only a small percentage of faculty hold tenure, but males hold at a higher percentage.

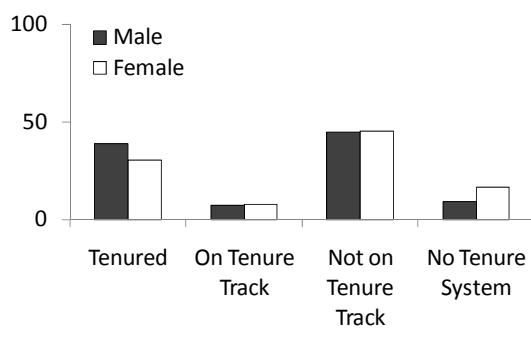

(a) Doctorate

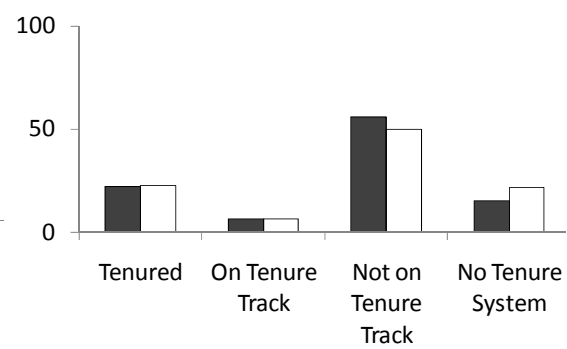

(b) Master's

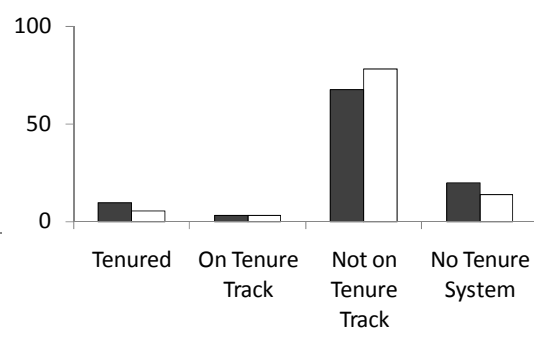

(c) Bachelor's

Figure 4 Two-Year, Highest Degree vs. Tenure Status for STEM Faculty ${ }^{5}$

\section{Part-Time versus Full-Time Employment}

One issue seen with faculty at two year schools is the larger percentage of faculty holding parttime appointments ${ }^{4}$. Do female STEM faculty members at two-year schools hold full-time appointments at percentages similar to their male counterparts? Table 6 shows that the rates are virtually identical. 
Table 6 Two-year, Gender vs. Employment Status for STEM Faculty - Percents ${ }^{5}$

\begin{tabular}{rrr}
\hline Gender & Full-Time & Part-Time \\
\hline Male & 36.9 & 63.1 \\
Female & 36.8 & 63.2 \\
\hline
\end{tabular}

\section{Job Satisfaction}

One last area to consider is satisfaction. The NSOPF specifically asks several questions regarding satisfaction. Of those, the two chosen to examine are overall satisfaction and interest in pursuing an academic career again 5 . Table 7 shows that male and female STEM faculty are very similar in their job satisfaction, at two-year schools. In fact, they are more likely to be "very satisfied" than their counterparts at four-year schools.

Table 7 Two-year and Four-year, Gender vs. Job Satisfaction for STEM Faculty - Percents ${ }^{5}$

\begin{tabular}{rrrrr} 
& \multicolumn{2}{c}{ 4-Year } & \multicolumn{2}{c}{ 2-Year } \\
\hline Overall Job Satisfaction & Male & Female & Male & Female \\
\hline Very satisfied & 43.3 & 41.3 & 53.4 & 53.5 \\
Somewhat satisfied & 43 & 44.7 & 39.2 & 38.8 \\
Somewhat dissatisfied & 11.2 & 11.2 & 5.4 & 6.6 \\
Very dissatisfied & 2.5 & 2.8 & 1.9 & 1.1 \\
\hline
\end{tabular}

Table 8 shows that when asked if they would pursue an academic career again, the responses were very similar across gender and school classification.

Table 8 Two-year and Four-year, Gender vs. Choosing Academic Career for STEM Faculty - Percents ${ }^{5}$

\begin{tabular}{rrrrr}
\cline { 2 - 5 } & \multicolumn{2}{c}{ 4-Year } & \multicolumn{2}{c}{ 2-Year } \\
\hline Choose academic career again & Male & Female & Male & Female \\
\hline Choose academic career & 90.4 & 88 & 89.8 & 90.7 \\
Not choose academic career & 9.6 & 12 & 10.2 & 9.3 \\
\hline
\end{tabular}

\section{Conclusions}

In this preliminary analysis of contemporary measures of success, by gender, of STEM faculty at two-year schools showed in many cases that faculty achieved success at similar rates. For rank, female faculty hold the higher ranks of associate and full professor at rates similar to their male counterparts. Females also hold graduate degrees at a similar rate. This preliminary analysis shows that the differences are not as large as at the four-year schools.

As part of a larger research program, each of these measures will be tested for significance. Where rates are not significantly different between two and four-year schools, qualitative analysis will be performed to determine what differences exist that allow female faculty to achieve at greater rates. In addition, areas of success which are not captured by the NSOPF data will be investigated through the qualitative analysis. 


\section{Bibliography}

1. Chronicle of Higher Education. Almanac 2004 2005. 2005.

2. National Science Foundation. Gender differences in the careers of academic scientists and engineers. Special Report NSF 04-323. Science Resources Statistics (NSF/SRS). [Online] 6 2004. [Cited: January 21, 2009.] http://www.nsf.gov/statistics/nsf04323/.

3. - . S\&E Degrees: 1966-2006. [Online] 2008. http://www.nsf.gov/statistics/nsf08321/pdf/nsf08321.pdf.

4. Provansnik, S and Planty, M. . Community colleges: Special supplement to the Condition of Education 2008

(NCES 2008-033). Washington, DC : National Center for Education Statistics, Institute of Education Sciences, U.S. Department of Education, 2008.

5. National Center for Education Statistics. National Study of Postsecondary Faculty (NSOPF:04). s.l. : U.S. Department of Education, 2004.

6. National Center for Educational Statistics. DAS Online - 2.0. Data Analsis System. [Online] 2009.

http://nces.ed.gov/dasolv2/tables/mainPage.asp?mode=NEW\&filenumber=28. 